\title{
First-Principles Studies for Electronic Structure and Optical Properties of $p$-Type Calcium Doped $\alpha-\mathrm{Ga}_{2} \mathrm{O}_{3}$
}

\author{
Abhay Kumar Mondal ${ }^{1}$, Mohd Ambri Mohamed ${ }^{1, *(\mathbb{D})}$, Loh Kean Ping ${ }^{1}{ }^{(D)}$, Mohamad Fariz Mohamad Taib ${ }^{2}$, \\ Mohd Hazrie Samat ${ }^{2,3}$, Muhammad Aniq Shazni Mohammad Haniff ${ }^{1}$ and Raihana Bahru ${ }^{1}$ (D) \\ 1 Institute of Microengineering and Nanoelectronics (IMEN), Universiti Kebangsaan Malaysia (UKM), \\ Bangi 43600, Selangor, Malaysia; abhay.nano17@gmail.com (A.K.M.); p103776@siswa.ukm.edu.my (L.K.P.); \\ aniqshazni@ukm.edu.my (M.A.S.M.H.); raihanabahru@ukm.edu.my (R.B.) \\ 2 Faculty of Applied Sciences, Universiti Teknologi MARA (UiTM), Shah Alam 40450, Selangor, Malaysia; \\ mfariz@uitm.edu.my \\ 3 Ionic Materials \& Devices (iMADE) Research Laboratory, Institute of Science, Universiti Teknologi \\ MARA (UiTM), Shah Alam 40450, Selangor, Malaysia; mohdhazrie@uitm.edu.my \\ * Correspondence: ambri@ukm.edu.my; Tel.: +603-8911-8558
}

Citation: Mondal, A.K.; Mohamed M.A.; Ping, L.K.; Mohamad Taib, M.F.; Samat, M.H.; Mohammad Haniff, M.A.S.; Bahru, R. First-Principles Studies for Electronic Structure and Optical Properties of $p$-Type Calcium Doped $\alpha-\mathrm{Ga}_{2} \mathrm{O}_{3}$. Materials 2021, 14, 604. https://doi.org/10.3390/ ma14030604

Received: 4 December 2020

Accepted: 20 January 2021

Published: 28 January 2021

Publisher's Note: MDPI stays neutral with regard to jurisdictional claims in published maps and institutional affiliations.

Copyright: (c) 2021 by the authors. Licensee MDPI, Basel, Switzerland. This article is an open access article distributed under the terms and conditions of the Creative Commons Attribution (CC BY) license (https:// creativecommons.org/licenses/by/ $4.0 /)$.

\begin{abstract}
Gallium oxide $\left(\mathrm{Ga}_{2} \mathrm{O}_{3}\right)$ is a promising wide-band-gap semiconductor material for UV optical detectors and high-power transistor applications. The fabrication of $p$-type $\mathrm{Ga}_{2} \mathrm{O}_{3}$ is a key problem that hinders its potential for realistic power applications. In this paper, pure $\alpha-\mathrm{Ga}_{2} \mathrm{O}_{3}$ and Ca-doped $\alpha-\mathrm{Ga}_{2} \mathrm{O}_{3}$ band structure, the density of states, charge density distribution, and optical properties were determined by a first-principles generalized gradient approximation plane-wave pseudopotential method based on density functional theory. It was found that calcium (Ca) doping decreases the bandgap by introducing deep acceptor energy levels as the intermediate band above the valence band maximum. This intermediate valence band mainly consists of Ca $3 p$ and $\mathrm{O} 2 \mathrm{p}$ orbitals and is adequately high in energy to provide an opportunity for $p$-type conductivity. Moreover, Ca doping enhances the absorptivity and reflectivity become low in the visible region. Aside, transparency decreases compared to the pure material. The optical properties were studied and clarified by electrons-photons interband transitions along with the complex dielectric function's imaginary function.
\end{abstract}

Keywords: first-principles; density functional theory; pure $\alpha-\mathrm{Ga}_{2} \mathrm{O}_{3}$; Ca-doped $\alpha-\mathrm{Ga}_{2} \mathrm{O}_{3}$; electronic structure; optical properties

\section{Introduction}

Gallium oxides $\left(\mathrm{Ga}_{2} \mathrm{O}_{3}\right)$ are entitled to five different polymorphs, namely $\alpha, \beta, \gamma, \varepsilon$, and $\delta$. Among them, corundum structure $\alpha-\mathrm{Ga}_{2} \mathrm{O}_{3}$ has emerged as a next-generation power semiconductor material for a sensor, solar-blind UV-photodetectors, photocatalyst, and high-power devices [1-4]. The ultra-wide bandgap semiconductor $\alpha-\mathrm{Ga}_{2} \mathrm{O}_{3}$ enables high temperature and high voltage device operation such as field-effect transistor (FET) and Schottky barrier diode (SBD). $\alpha-\mathrm{Ga}_{2} \mathrm{O}_{3}$ is privillaged of superior properties such as a smaller electron effective mass, higher breakdown field, and larger Baliga figure of merit [5-7] which have capabilities to go beyond existing technologies to $4 \mathrm{H}-\mathrm{SiC}(3.26 \mathrm{eV})[8]$ and $\mathrm{GaN}(3.44 \mathrm{eV})$ in the power industry [9].

Band structure engineering would open new avenues in device applications [10]. Doping with particular elements in practical applications can boost the material's electrical and optical properties and maximize the devices' efficiency. Mostly, $\alpha-\mathrm{Ga}_{2} \mathrm{O}_{3}$ is privileged with good $n$-type doping conductivity due to its deep donor oxygen defect nature [11]. Silicon (Si) and Tin (Sn) are highly studied $n$-type shallow donors with a small ionization energy [11,12]. In contrast, high-quality $p$-type $\alpha-\mathrm{Ga}_{2} \mathrm{O}_{3}$ is challenging due to the lack of hole conductivity, low solubility, and activation rate of dopants which largely impede 
the formation of the $p-n$ junction bipolar semiconductor devices [13-16]. Despite several experimental reports on $\alpha-\mathrm{Ga}_{2} \mathrm{O}_{3}$, its theoretical analysis is relatively small and started to receive attention recently. The theoretically predicted Gr-I and Gr-II metals shows p-type nature by doping on $\mathrm{Ga}_{2} \mathrm{O}_{3}$ as reported by Tang et al. [17]. In 2019, Dong et al. investigated the magnesium $(\mathrm{Mg})$ element substitute at the gallium site that had proven to be a good $p$-type conductivity in $\alpha-\mathrm{Ga}_{2} \mathrm{O}_{3}$ through first-principles studies [18]. Tang et al. reported that the same alkaline earth metal group, calcium $(\mathrm{Ca})$, plays a deep acceptor element and studied the electronic structures and optical properties of $p$-type Ca doped on a $\beta-\mathrm{Ga}_{2} \mathrm{O}_{3}$ first-principle calculation [17]. There is a lack of in-depth analysis and systematic study of new strong acceptor doping studies for the bipolar $p-n$ junction of electronic and optical $\alpha-\mathrm{Ga}_{2} \mathrm{O}_{3}$ devices, which is of high demand for further exploration of potential $\alpha-\mathrm{Ga}_{2} \mathrm{O}_{3}$ films.

In this research, Gr-IIA alkaline metal Ca doping $\alpha-\mathrm{Ga}_{2} \mathrm{O}_{3}$ had reported the electronic structure and optical properties by the first-principles studies based on density functional theory (DFT). The work aims to find Ca potential by substituting the Ga site and supporting this theoretical investigation for future experimental work. Ca attributes of small ionization energy quickly release holes and show $p$-type conductivity nature. The doping of $\mathrm{Ca}$ contributes to a slight reduction in the optical bandgap due to the addition of the impurity band into the valance band (VB). The optical absorption spectra have shown a redshift of the absorption edge towards the visible-infrared region.

\section{Computational Details}

In this study, all the calculations were performed by using the Cambridge Serial Total Energy Package (CASTEP) code in Materials Studio (MS) 6.1 software based on the DFT [19]. The ultra-soft pseudopotential approach is used for general energy. The electronic wave function is unfolded with plane wave base groups, and ion potential is replaced by ultra-soft pseudopotential [20]. Ultrasoft pseudopotentials technology interacts with ions and electrons with total energy convergence $5 \times 10^{-6} \mathrm{eV} /$ atom [21]. Cut-off plane-wave energy is set at $380 \mathrm{eV}$ for total-energy, band structure, and spectra calculations. It has been shown that this functional exchange-correlation gives rise to widegap semiconductor atomic geometries with strong ionic bonds in excellent accordance with measured values. The exchange-correlation potential is defined by the generalized gradient approximation (GGA) in the Perdew-Burke-Ernzerhof (PBE) function and the local density approximation (LDA) [22]. The LDA utilization in this simulation work was used to compare the parameters, cell volume, and cell angle from the feature of the GGA-PBE. The electronic and optical characterization is then determined based on the structural geometry optimization to make the calculations effective and trackable [18]. The optimization of all calculated structures was done until the Hellmann Feynman force became less than $0.01 \mathrm{eV} / \AA(1 \AA=0.1 \mathrm{~nm})$. Broyden-Fletcher-Goldfarb Shanno (BFGS) is a reliable approach to optimize the structure by full relaxation of the lattice constant and internal coordinates [23]. For maximum stress and displacement, the convergence criterion was $0.02 \mathrm{GPa}$ and $5 \times 10^{-4} \AA$, respectively. A primitive cell composed of 30 atoms (12 Ga atoms and $18 \mathrm{O}$ atoms) was used to study the electronic structure and optical properties of the Ca doped $\alpha-\mathrm{Ga}_{2} \mathrm{O}_{3}$. A $3 \times 3 \times 2$ k-point mesh of Monkhorst-Pack methods was used to integrate the Brillouin zone [24]. Ga, $\mathrm{O}$, and $\mathrm{Ca}$ valence shell electrons configuration were $[\mathrm{Ar}] 3 \mathrm{~d}^{10} 4 \mathrm{~s}^{2} 4 \mathrm{p}^{1},[\mathrm{He}] 2 \mathrm{~s}^{2} 2 \mathrm{p}^{4}$, and [Ar] $4 \mathrm{~s}^{2}$, respectively.

\section{Results and Discussion}

\subsection{Geometrical Structures}

Firstly, geometry optimization was implemented using the BFGS method [25]. The most stable structure was achieved after the fully relaxed cell parameter and volume by reducing the energy state [20]. The investigated optimized crystal structure of intrinsic $\alpha-\mathrm{Ga}_{2} \mathrm{O}_{3}$ and Ca-doped $\alpha-\mathrm{Ga}_{2} \mathrm{O}_{3}$ is shown in Figure $1 \mathrm{a}, \mathrm{b}$. The lattice parameters $\mathrm{a}, \mathrm{b}, \mathrm{c}$, 
and unit cell volume $\mathrm{V}$ are increased after $\mathrm{Ca}$ doping due to the larger atomic radius of $\mathrm{Ca}$ than that of Ga. Meanwhile, the bandgap $\mathrm{E}_{\mathrm{g}}$ decreases with Ca doping.

(a)

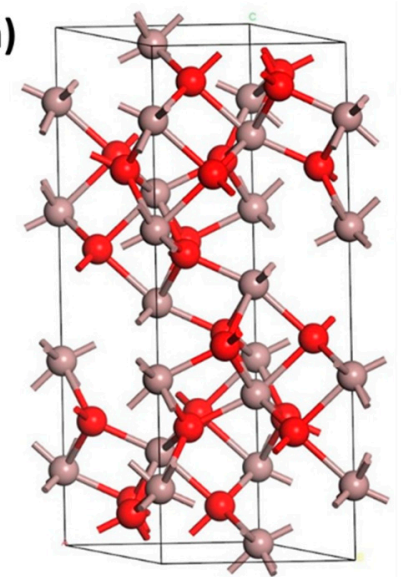

(b)

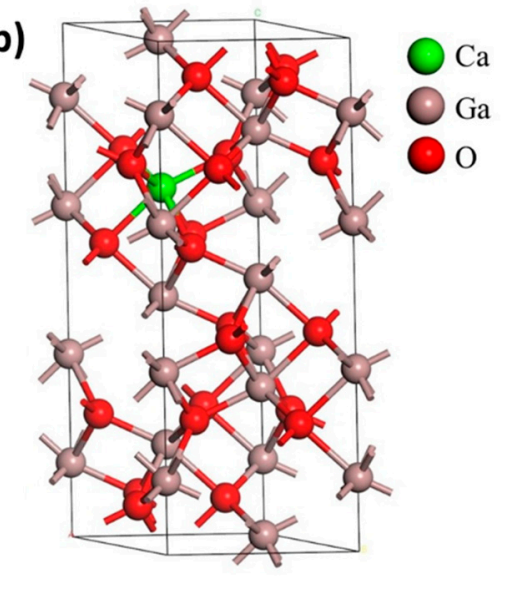

Figure 1. The crystal structure of the primitive cell (a) intrinsic $\alpha-\mathrm{Ga}_{2} \mathrm{O}_{3}$ and (b) Ca-doped $\alpha-\mathrm{Ga}_{2} \mathrm{O}_{3}$. $\mathrm{Ga}, \mathrm{O}$, and $\mathrm{Ca}$ atoms are denoted by brown, red, and green colors, respectively.

Figure 1 shows the typical corundum structure of $\alpha-\mathrm{Ga}_{2} \mathrm{O}_{3}$ with $\mathrm{R} \overline{\mathrm{c}} \mathrm{c}$ symmetry, and the crystalline cell comprises six $\mathrm{Ga}_{2} \mathrm{O}_{3}$ formula units. In the unit cell of $\alpha-\mathrm{Ga}_{2} \mathrm{O}_{3}$, oxygen anions are almost closely hexagonally packed, and gallium atoms occupy octahedral twothird sites. Every gallium octahedron shares one face and three edges with the other three octahedra sites. The gallium octahedral sites are distorted by the crystal lattice [7]. We investigated and explored the electronic and optical properties of Ca doped $\alpha-\mathrm{Ga}_{2} \mathrm{O}_{3}$ by substitution of $\mathrm{Ga}$ atoms lowest energy preferred sites. Table 1 lists all the optimized lattice parameters, and cell volume of pure and Ca doped $\alpha-\mathrm{Ga}_{2} \mathrm{O}_{3}$ material as compared to experimental results $(\mathrm{a}=\mathrm{b}=4.983, \mathrm{c}=13.433)$ [26]. The experimental value for $\alpha-\mathrm{Ga}_{2} \mathrm{O}_{3}$ has a lattice parameter and cell volume closer to that of the LDA calculation. In addition, the error is less than $1.5 \%$, ensuring the reliability of our results. It has been shown that the calculated LDA is more precise and accurate than GGA-PBE according to the experimental reports on the lattice parameter of hexagonally structured $\alpha-\mathrm{Ga}_{2} \mathrm{O}_{3}$. Therefore, in this study, the electronic structure and optical properties of $\mathrm{Ca}$ doped $\alpha-\mathrm{Ga}_{2} \mathrm{O}_{3}$ were calculated using the DFT-LDA approach.

Table 1. The lattice parameters $(a, b$, and $c)$ and unit cell volume (V) of basic $\alpha-\mathrm{Ga}_{2} \mathrm{O}_{3}$ and Ca doped $\alpha-\mathrm{Ga}_{2} \mathrm{O}_{3}$ crystal structure. The values were compared with theoretical and experimental results.

\begin{tabular}{|c|c|c|c|c|c|}
\hline Phase & & a (§̊) & b (̊̊) & c ( $(\AA)$ & $V\left(\AA^{3}\right)$ \\
\hline \multirow{5}{*}{ Pure $\mathrm{Ga}_{2} \mathrm{O}_{3}$} & LDA-CAPZ & $4.965(-0.36 \%)$ & $4.965(-0.36 \%)$ & $13.338(-0.71 \%)$ & $284.747(-1.42 \%)$ \\
\hline & GGA-PBE & $5.074(1.83 \%)$ & $5.074(1.83 \%)$ & $13.664(1.72 \%)$ & $304.656(5.47 \%)$ \\
\hline & GGA-PBEsol & $5.028(0.90 \%)$ & $5.028(0.90 \%)$ & $13.511(0.58 \%)$ & $295.807(2.41 \%)$ \\
\hline & GGA-PBE (CASTEP) [6] & 5.07 & 5.07 & 13.67 & 304.309 \\
\hline & Expt. [26] & 4.983 & 4.983 & 13.433 & 288.859 \\
\hline Ca-Doped $\mathrm{Ga}_{2} \mathrm{O}_{3}$ & LDA-CAPZ & $5.010(0.54 \%)$ & $5.010(0.54 \%)$ & $13.520(0.647 \%)$ & $293.889(1.74 \%)$ \\
\hline
\end{tabular}

The bond lengths for pure and Ca-doped $\alpha-\mathrm{Ga}_{2} \mathrm{O}_{3}$ are shown in Table 2. It is shown that the atomic radius of the $\mathrm{Ga}$ atom is smaller than that of the $\mathrm{Ca}$ atom according to the periodic table. Therefore, the $\mathrm{Ga}-\mathrm{O}$ bond length is shorter than the $\mathrm{Ca}-\mathrm{O}$ and $\mathrm{O}-\mathrm{O}$ bonds in Ca-doped $\alpha-\mathrm{Ga}_{2} \mathrm{O}_{3}$. This situation is the same as the pure $\alpha-\mathrm{Ga}_{2} \mathrm{O}_{3}$, where the $\mathrm{Ga}-\mathrm{O}$ bond length is shorter than $\mathrm{O}-\mathrm{O}$ bonds. After Ca doping, the overall bond length is larger than before doping due to the concentration of $\mathrm{Ca}^{2+}$ ions. 
Table 2. The calculated bond length of undoped and Ca-doped $\alpha-\mathrm{Ga}_{2} \mathrm{O}_{3}$.

\begin{tabular}{ccc}
\hline Type of Bond Length & Pure $\boldsymbol{\alpha}-\mathrm{Ga}_{\mathbf{2}} \mathbf{O}_{\mathbf{3}}$ & Ca-doped $\boldsymbol{\alpha}-\mathrm{Ga}_{\mathbf{2}} \mathbf{O}_{\mathbf{3}}$ \\
\hline $\mathrm{Ga}-\mathrm{O}(\AA)$ & 1.989 & 1.993 \\
$\mathrm{O}-\mathrm{O}(\AA)$ & 2.762 & 2.741 \\
$\mathrm{Ca}-\mathrm{O}(\AA)$ & - & 2.253 \\
\hline
\end{tabular}

\subsection{Electronic Structure}

\subsubsection{Electron Charge Density}

The ionic and covalent bonding-based charge density contours of intrinsic $\alpha-\mathrm{Ga}_{2} \mathrm{O}_{3}$ and Ca-doped $\alpha-\mathrm{Ga}_{2} \mathrm{O}_{3}$ are shown in Figure $2 \mathrm{a}$,b, respectively. The charge density distributions can be used to assess crystal bonding characteristics. In $\alpha-\mathrm{Ga}_{2} \mathrm{O}_{3}$, the ionic or covalent structures are a contentious subject and have vital facts to understand the charge transport property $[23,24]$. The nuclei are bound by the charge density, which is shared between them. It has been shown that certain covalent bonding characters can exist between Ga and $\mathrm{O}$ atoms [24]. The electrons are located around the $\mathrm{O}$ atoms in the hexagonal phases, and there is no region of bond localization, indicating a predominantly ionic bond.
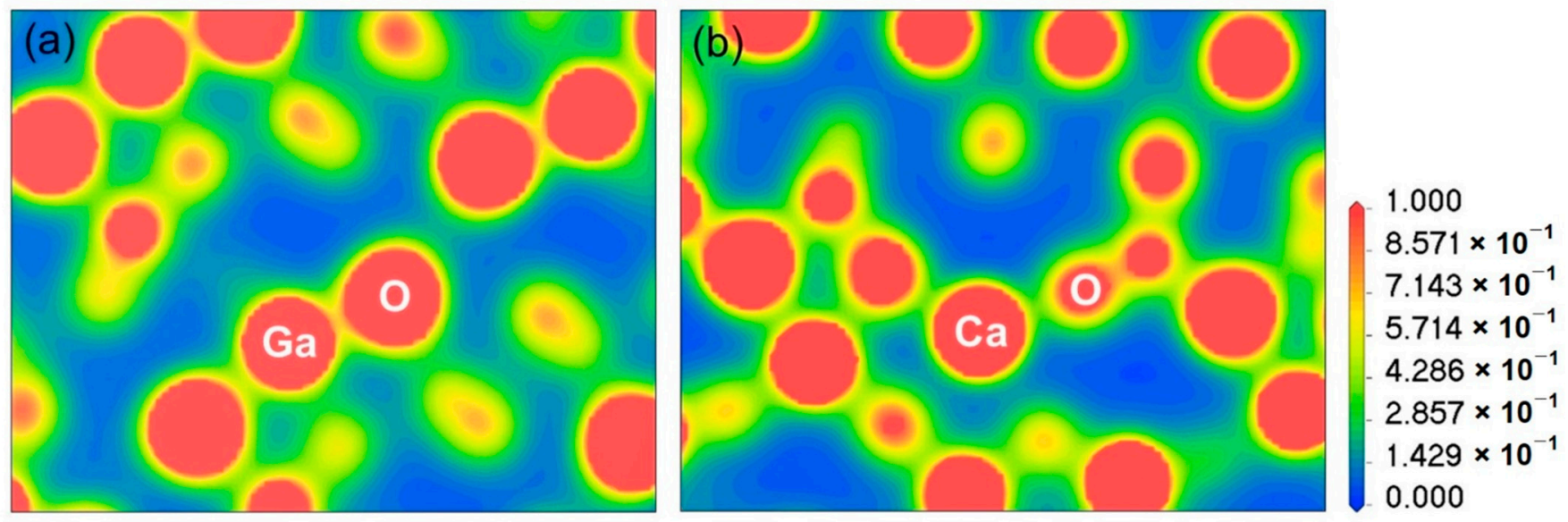

Figure 2. Distribution of electron density of (a) pure $\alpha-\mathrm{Ga}_{2} \mathrm{O}_{3}$ and (b) Ca-doped $\alpha-\mathrm{Ga}_{2} \mathrm{O}_{3}$.

In Figure $2 b$, a major reflection is observed in the distribution of charge density between the doping $\mathrm{Ca}$ atom and native atoms. By incorporating $\mathrm{Ca}$, the oxygen atom's nearest electrons population reduce compared to distant oxygen atoms, as presented in Figure $2 \mathrm{~b}$. Consequently, only the closest few electrons of the $\mathrm{O}$ atom donate to the $\mathrm{Ca}$ atom, leaving holes in the $\mathrm{O}$ atom to be $p$-type. The $\mathrm{Ca}$ atom loses all valence electrons while the electron density around the $\mathrm{O}$ atoms increases evidently and further decreases in the region between the $\mathrm{Ca}$ atom and the nearest $\mathrm{O}$ atom. A strong ionic bonding appears between $\mathrm{Ca}$ and the nearest neighbor $\mathrm{O}$ atoms. Meanwhile, $\mathrm{Ca}$-doped $\alpha-\mathrm{Ga}_{2} \mathrm{O}_{3}$ gives the outer shell electrons $4 s^{2}$ and partial $3 p^{6}$ electrons of $\mathrm{Ca}$ atoms coupled with $\mathrm{O} 2 \mathrm{p}$ electrons.

\subsubsection{Band Structure and Density of States}

The first-principal calculations of the electronic band structure of undoped $\alpha-\mathrm{Ga}_{2} \mathrm{O}_{3}$ are shown in Figure 3a. The density of states is shown in Figure 4a,c at different energy windows. The bandgap energy is usually determined between the valence band maximum (VBM) and the conduction band minimum (CBM), placed at the Brillion region's $G$ point. The Fermi level is situated at $0 \mathrm{eV}$ of the energy scale. The large disparity of theoretically calculated DFT-LDA bandgap $(2.950 \mathrm{eV})$ and experimental band gap $(5.3 \mathrm{eV})$ is due to the ground state DFT results of strong Coulomb correlation and exchange-correlation potential between the excited electrons in the underestimated LDA bandgap [27]. 

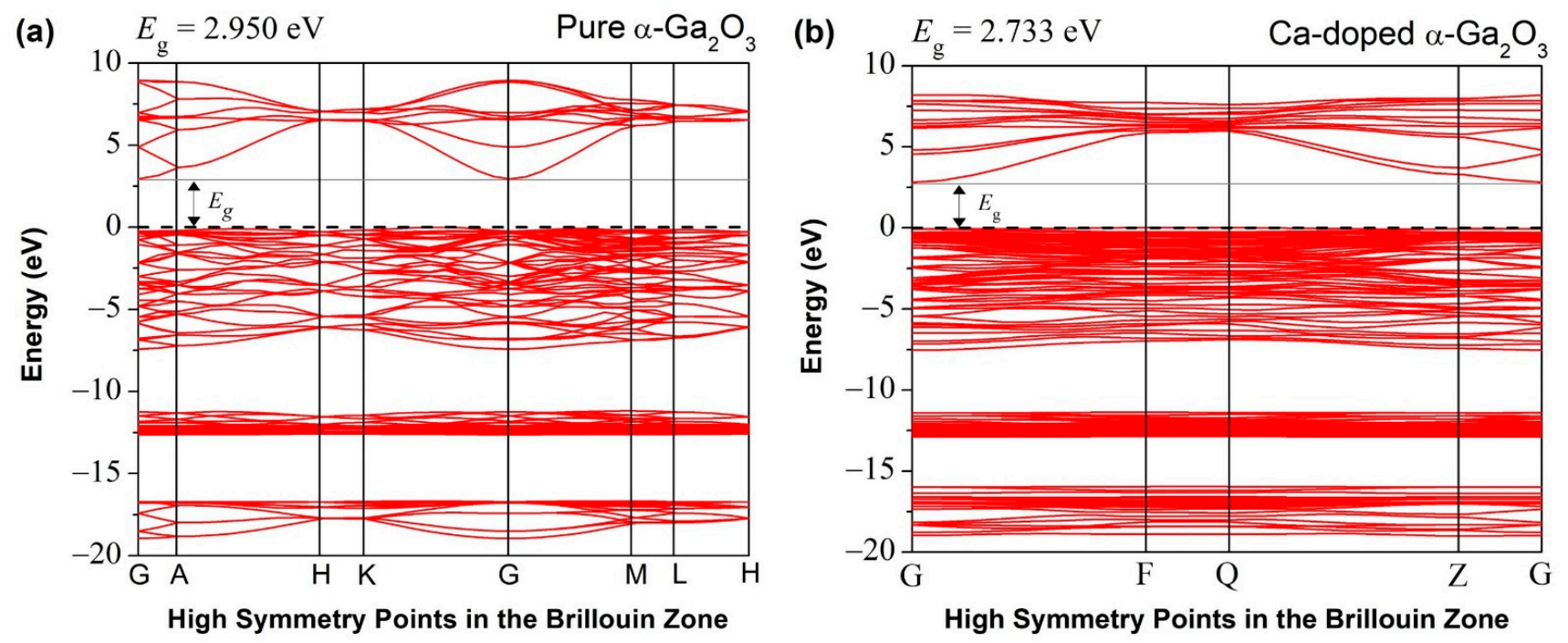

Figure 3. Energy band structure diagram of (a) pure $\alpha-\mathrm{Ga}_{2} \mathrm{O}_{3}$ and (b) Ca-doped $\alpha-\mathrm{Ga}_{2} \mathrm{O}_{3}$; Fermi level is set to zero.
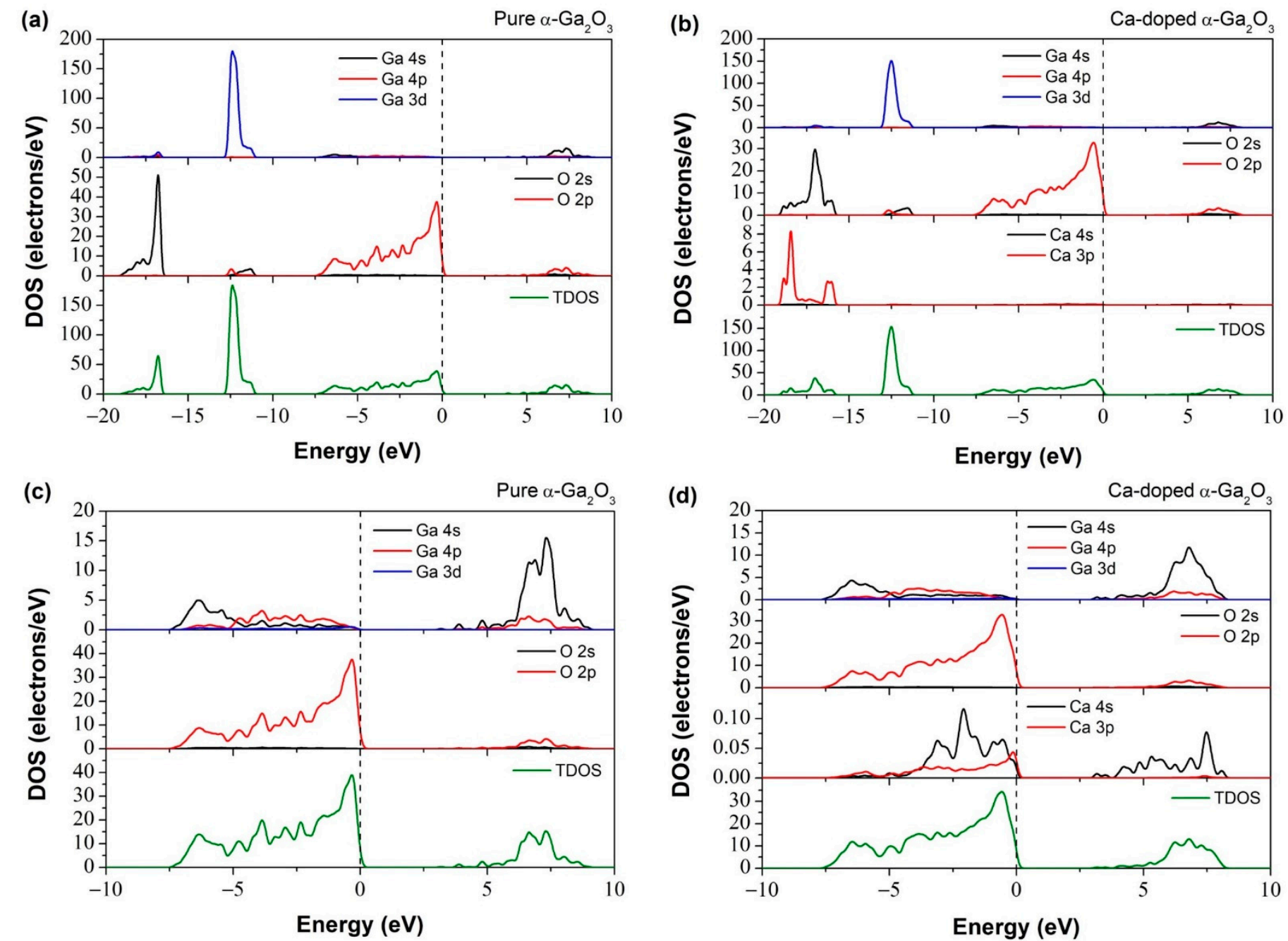

Figure 4. The density of states of (a) pure $\alpha-\mathrm{Ga}_{2} \mathrm{O}_{3}$, (b) Ca-doped $\alpha-\mathrm{Ga}_{2} \mathrm{O}_{3}$, (c) pure $\alpha-\mathrm{Ga}_{2} \mathrm{O}_{3}$ ( -10 to 10 energy window), and (d) Ca-doped $\alpha-\mathrm{Ga}_{2} \mathrm{O}_{3}$ ( -10 to 10 energy window). 
The electronic band structure of pure $\alpha-\mathrm{Ga}_{2} \mathrm{O}_{3}$, as shown in Figure 3a, is represented by the crystal structure made with the $12 \mathrm{Ga}$ atoms and $18 \mathrm{O}$ atoms of primitive cells. Figure $4 \mathrm{a}$ shows the uppermost valence band is a major contribution of $\mathrm{O} 2 \mathrm{p}$ states with a width from about -0.12 to $-7.43 \mathrm{eV}$ and a minor contribution of $\mathrm{Ga} 3 \mathrm{~d}, 4 \mathrm{p}$, $4 \mathrm{~s}$, and $\mathrm{O}$ 2 s orbitals which are located between -11.5 and $-18.5 \mathrm{eV}$. CBM consists of Ga $4 \mathrm{~s}$ orbital states, and lies between 2.32 to $8.46 \mathrm{eV}$ [26]. The valence band's edge is reasonably flat, and the effective mass at VBM is relatively heavy. Characteristics of CBM is almost equally dispersed everywhere.

The electronic band structure of Ca-doped $\alpha-\mathrm{Ga}_{2} \mathrm{O}_{3}$ is shown in Figure $3 b$, and its corresponding DOS is shown in Figure $4 b, d$, at different energy values. The acceptor dopant has been introduced above the valence band and intersected with the Fermi level. The $\mathrm{Ca}-\alpha-\mathrm{Ga}_{2} \mathrm{O}_{3}$ has a direct bandgap with the most upper part of the valence band and the lowest part of the $\mathrm{G}$ point's conduction band. It is noticed that the DFT-LDA calculated bandgap of Ca-doped $\alpha-\mathrm{Ga}_{2} \mathrm{O}_{3}$ is $2.733 \mathrm{eV}$ which is $0.217 \mathrm{eV}$ less than that of pure $\alpha-\mathrm{Ga}_{2} \mathrm{O}_{3}$. In Ca-doped systems, the Ca 3 p state contributes to the VBM, and the CBM is contributed to by Ga-4s and Ca-3p states. Ca creates dopant states near the topmost of VBs and shift the valence band edge at higher energy and reduce the bandgap.

The Ca 4 s state shows very narrow bands at -15.79 to -19.02 in Figure $4 \mathrm{~b}$. The impurity levels lead to the excess holes over the upper part of the valence band [27]. The Ca doped cases' highest occupy degree shifts dramatically downward by $0.12 \mathrm{eV}$ due to the far higher energy of $\mathrm{Ca} 4 \mathrm{~s}$ compared to $\mathrm{Ga} 3$ s orbitals. At around -16.1 to $-18.6 \mathrm{eV}$, six bands are mainly composed of $\mathrm{O} 2 \mathrm{~s}$ states and at $2.07-6.94 \mathrm{eV}$, six bands are mainly composed of $\mathrm{O} 2 \mathrm{p}$ states (Figure $4 \mathrm{~b}$ ). At around -11.2 to $-12.9 \mathrm{eV}, 20$ bands consist mainly of $\mathrm{Ga} 3 \mathrm{~d}$ states.

$\left(\mathrm{Ga}_{1-\mathrm{x}} \mathrm{Ca}_{\mathrm{x}}\right)_{2} \mathrm{O}_{3}$ alloys bandgap energy with the incorporation of $\mathrm{Ca}$ impurity is schematically shown in Figure 5 . In $\alpha-\mathrm{Ca}_{2} \mathrm{O}_{3}, 3.33 \%$ of $\mathrm{Ca}$ concentrations were produced by replacing one $\mathrm{Ga}$ atom with $\mathrm{Ca}$, respectively. Ca substitutes $\mathrm{Ga}$ octahedral sites and fully occupied band energy higher than the original valence band of the $\mathrm{Ga}_{2} \mathrm{O}_{3}$. This intermediate band originates from the coupling of $\mathrm{Ca} 3 \mathrm{p}$, which lies below the $\mathrm{O} 2 \mathrm{p}$ band that forms the higher-lying valence bands, as shown in Figure 5. Furthermore, the intermediate valence band shows that a downward movement of the CBM was formed, attributed to the attraction between the $\mathrm{Ca}$ intermediate valence band and the CBM of the host. This situation resulted in a decrease in the bandgap of the $\left(\mathrm{Ga}_{1-x} \mathrm{Ca}_{\mathrm{x}}\right)_{2} \mathrm{O}_{3}$ alloy with the doping of $\mathrm{Ca}$.

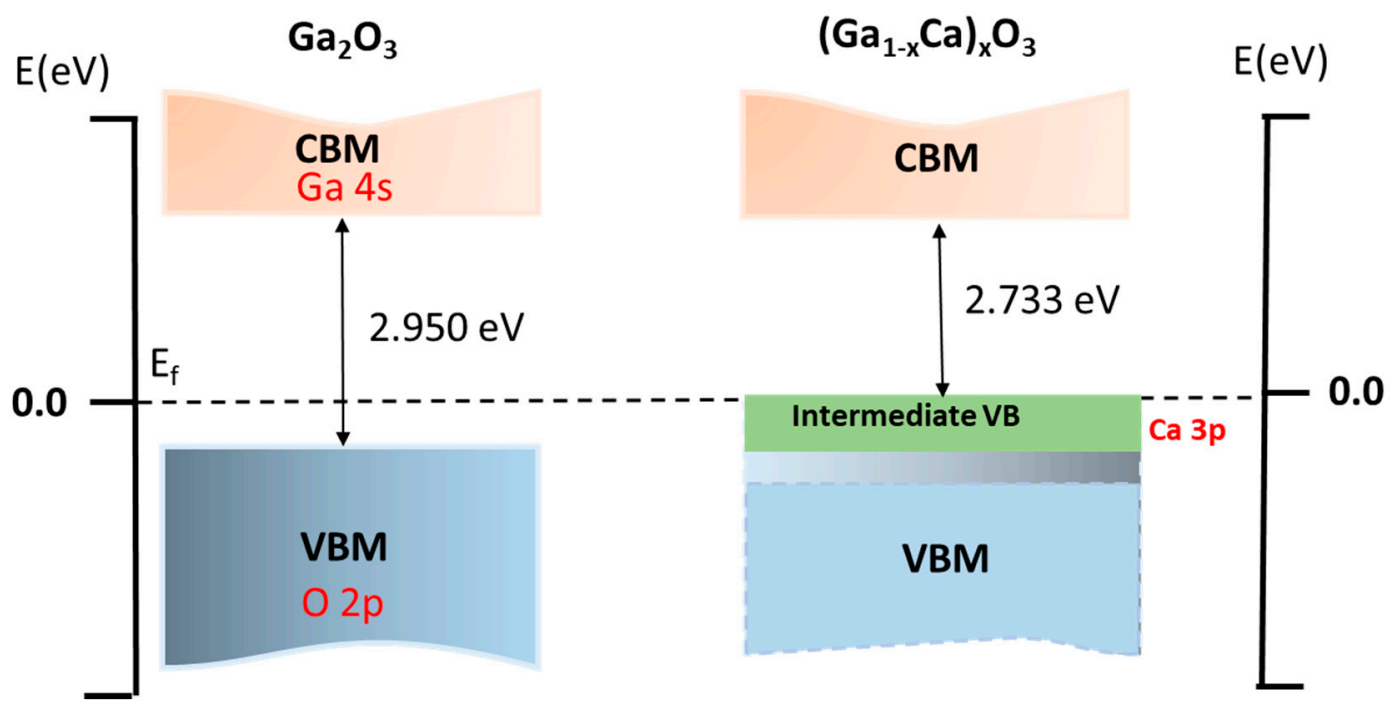

Figure 5. Schematic representation of the effects of adding Ca on the electronic band structure of $\alpha-\mathrm{Ga}_{2} \mathrm{O}_{3}$. $\left(\mathrm{Ga}_{1-\mathrm{x}} \mathrm{Ca}_{\mathrm{x}}\right)_{2} \mathrm{O}_{3}$ with $\mathrm{x}=1 / 30$. All energies are in $\mathrm{eV}$. The bands showed in green represent the intermediate valence band, composed of hybridized Ca $3 p$ and $\mathrm{O} 2 \mathrm{p}$ orbitals. 


\subsection{Optical Properties}

\subsubsection{Theoretical Description and Optical Properties}

The optical properties of pure $\alpha-\mathrm{Ga}_{2} \mathrm{O}_{3}$ and Ca doped $\alpha-\mathrm{Ga}_{2} \mathrm{O}_{3}$ can be studied based on the dielectric function, absorption coefficient, and reflectivity. The optical transitions are related to inter-band and intra-band transitions in the crystal structure of solid materials. The inter-band transitions mainly contributed to the semiconductor rather than intraband transitions to semiconducting crystal structure. The dielectric function $\varepsilon(\omega)$ has a frequency dependence linear electromagnetic interaction response of incident photons with electrons and is separated into the real part $\varepsilon_{1}(\omega)$ and imaginary part $\mathrm{i} \varepsilon_{2}(\omega)$. It is difficult to achieve accurate optical constants due to the underestimation of the bandgap. Hence, the optical property results were corrected by scissors operators according to experimental results. Scissors operators $=5.3 \mathrm{eV}-2.950 \mathrm{eV}=2.35 \mathrm{eV}$, where 2.950 is theoritical DFT-LDA calculated bandgap and $5.3 \mathrm{eV}$ is experimental bandgap [28]. The scissors operators used to shift all conduction levels to match the measured value of the bandgap. All-optical properties can be described from the complex dielectric constant in Equation (1) [29]:

$$
\varepsilon(\omega)=\varepsilon_{1}(\omega)+i \varepsilon_{2}(\omega)
$$

The imaginary dielectric part $\varepsilon_{2}(\omega)$ semiconductors are an essential parameter for determining optical properties for different designs of optoelectronic devices. The dielectric function imaginary part $\varepsilon_{2}(\omega)$ is associated with the dielectric loss of energy or absorption of light described by the absorption coefficient in the material while the real part $\varepsilon_{1}(\omega)$ is associated with the stored energy within the material (degree of polarization). The complex dielectric function imaginary part $\varepsilon_{2}(\omega)$ is determined by summing the transitions between occupied and unoccupied electronic states, as reported in Equation (2) [22]:

$$
\varepsilon_{2}(\omega)=\left(\frac{4 \pi^{2} e^{2}}{m \omega^{2}}\right) \sum_{i, j} \int\langle i|M| j\rangle^{2} f_{i}\left(1-f_{i}\right) \times \delta\left(E_{j k}-E_{i k}-\omega\right) d^{3} k
$$

where $\mathrm{m}$ is the mass of free electrons, $\mathrm{e}$ is the electron charge, $\mathrm{M}$ is the dipole matrix, and $\omega$ is the frequency of incident photons. $i$ and $j$ are the initial and final states, respectively, $f_{i}$ denotes the Fermi distribution function and $i$-th state with wave function vector $k$. The dielectric function real part $\varepsilon_{1}(\omega)$ can be derived from the imaginary part $i \varepsilon_{2}(\omega)$ by the Kramers-Kronig dispersion Equation (3) [30]:

$$
\varepsilon_{1}(\omega)=1+\frac{2}{\pi} P \int_{0}^{8} \frac{\omega \varepsilon(\grave{\omega}) d \omega}{\left(\grave{\omega}^{2}-\omega^{2}\right)}
$$

where $\mathrm{P}$ is the principal value of the integral. The absorption coefficient can be derived from the dielectric function as shown in Equation (4) [31]:

$$
\alpha(\omega)=\sqrt{2}(\omega)\left[\sqrt{\varepsilon_{1}(\omega)^{2}+\varepsilon_{2}(\omega)^{2}}-\varepsilon_{1}(\omega)\right]^{1 / 2}
$$

\subsubsection{Dielectric Function}

The dielectric constant is directly proportional to the crystal's polarizability, representing the deformability of the electronic distribution, and relates the shape of the valence band charge density. Oxygen ions are supposed to contribute to polarizability in such a highly ionic substance as $\mathrm{Ga}_{2} \mathrm{O}_{3}$. As was predicted in the current study, a difference of dielectric properties between $\mathrm{Ca}$ and $\alpha-\mathrm{Ga}_{2} \mathrm{O}_{3}$ is projected. A considerably larger dielectric constant of $\alpha-\mathrm{Ga}_{2} \mathrm{O}_{3}$ compared to Ca doped $\alpha-\mathrm{Ga}_{2} \mathrm{O}_{3}$ can be drawn to a lightly dense ion package and a large number of $\mathrm{Ga}$ atoms coordinated in the $\alpha-\mathrm{Ga}_{2} \mathrm{O}_{3}$ lattice [7].

From Figure 6, the calculated imaginary dielectric function of intrinsic $\alpha-\mathrm{Ga}_{2} \mathrm{O}_{3}$ and $\mathrm{Ca}-\alpha-\mathrm{Ga}_{2} \mathrm{O}_{3}$ were plotted and compared. The main peaks are $10.12 \mathrm{eV}$ of pure and Cadoped $\alpha-\mathrm{Ga}_{2} \mathrm{O}_{3}$, respectively, corresponding to the electrons' transitions from the upper 
state $\mathrm{O}-2 \mathrm{p}$ valence band to the lower state $\mathrm{Ga}-4$ s conduction band. The Ca-doped $\alpha-\mathrm{Ga}_{2} \mathrm{O}_{3}$ peak is smaller than that of intrinsic $\alpha-\mathrm{Ga}_{2} \mathrm{O}_{3}$ and is enhanced towards the lower energy site. Moreover, this $\mathrm{Ca}$ doping absorption peak at $2.9 \mathrm{eV}$ indicates that the absorption spectra increase from the UV to the visible region, and the average optical transmittance decreases.

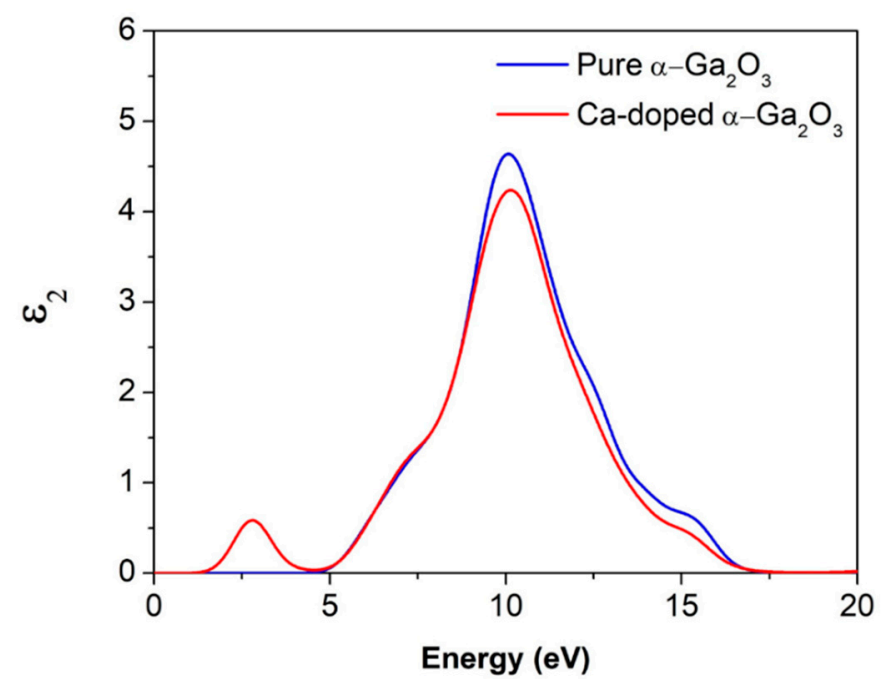

Figure 6. The imaginary part of the complex dielectric function for intrinsic $\alpha-\mathrm{Ga}_{2} \mathrm{O}_{3}$ and Ca doped $\alpha-\mathrm{Ga}_{2} \mathrm{O}_{3}$.

\subsubsection{Absorption and Reflectivity}

The absorption spectra of intrinsic $\alpha-\mathrm{Ga}_{2} \mathrm{O}_{3}$ and Ca-doped $\alpha-\mathrm{Ga}_{2} \mathrm{O}_{3}$ in the range of energy $(0$ to $40 \mathrm{eV})$ and wavelength $(0-1000 \mathrm{~nm})$ are shown in Figure $7 \mathrm{a}, \mathrm{b}$. The presence of a high energy peak at $11.5 \mathrm{eV}$ into the deep ultraviolet region is shown in both cases of $\alpha-\mathrm{Ga}_{2} \mathrm{O}_{3}$ and $\mathrm{Ca}$-doped $\alpha-\mathrm{Ga}_{2} \mathrm{O}_{3}$. These peaks are associated with the inter-band transition from the valance band $\mathrm{O} 2 \mathrm{p}$ occupied states to the conduction band $\mathrm{Ga} 4 \mathrm{~s}$ unoccupied states. From Figure $7 \mathrm{a}$, it is worth noticing that the absorptivity of $\alpha-\mathrm{Ga}_{2} \mathrm{O}_{3}$ is in the deep UV spectrum due to its semi-insulating nature. Meanwhile, Ca-doped $\alpha-\mathrm{Ga}_{2} \mathrm{O}_{3}$ appears as a sharp new small peak at $2.9 \mathrm{eV}$ which originated from the inter-band transitions of $\mathrm{C} 3 \mathrm{p}$ from the VBM to these CBM that promote $\varepsilon_{2}$ and enhanced absorption in the visible region.

Figure $7 \mathrm{a}, \mathrm{b}$ show that the absorption spectra have a redshift with the Ca-doping. This shifting is mainly because of the hole carriers generated after the Ca doping so that the Fermi level enters the valence band, which is realized in the density of the states. The same phenomenon was observed in the absorption spectrum wavelength window in both cases of undoped and $\mathrm{Ca}$ doped $\alpha-\mathrm{Ga}_{2} \mathrm{O}_{3}$ (Figure $7 \mathrm{~b}$ ). As shown in Figure $7 \mathrm{~b}$, the absorption spectra indicate that the transparency decreases with Ca doping due to enhancement of absorbance in the visible region.

Figure $7 \mathrm{c}, \mathrm{d}$ show the reflection spectra of intrinsic $\alpha-\mathrm{Ga}_{2} \mathrm{O}_{3}$ and $\mathrm{Ca}$-doped $\alpha-\mathrm{Ga}_{2} \mathrm{O}_{3}$ in the energy and wavelength window regime. For pure $\alpha-\mathrm{Ga}_{2} \mathrm{O}_{3}$, a sharp main intense peak appears at $16 \mathrm{eV}$ in the energy range and $70.45 \mathrm{~nm}$ in the wavelength range, and it decreases from the deep UV-visible to infrared region. Meanwhile, for the Ca doped $\alpha-\mathrm{Ga}_{2} \mathrm{O}_{3}$ system, two major peaks appear at the same position as the pure phase, but reflectivity is lower than that of the pure one. These characters drag material potential towards optoelectronics and bipolar device application. 

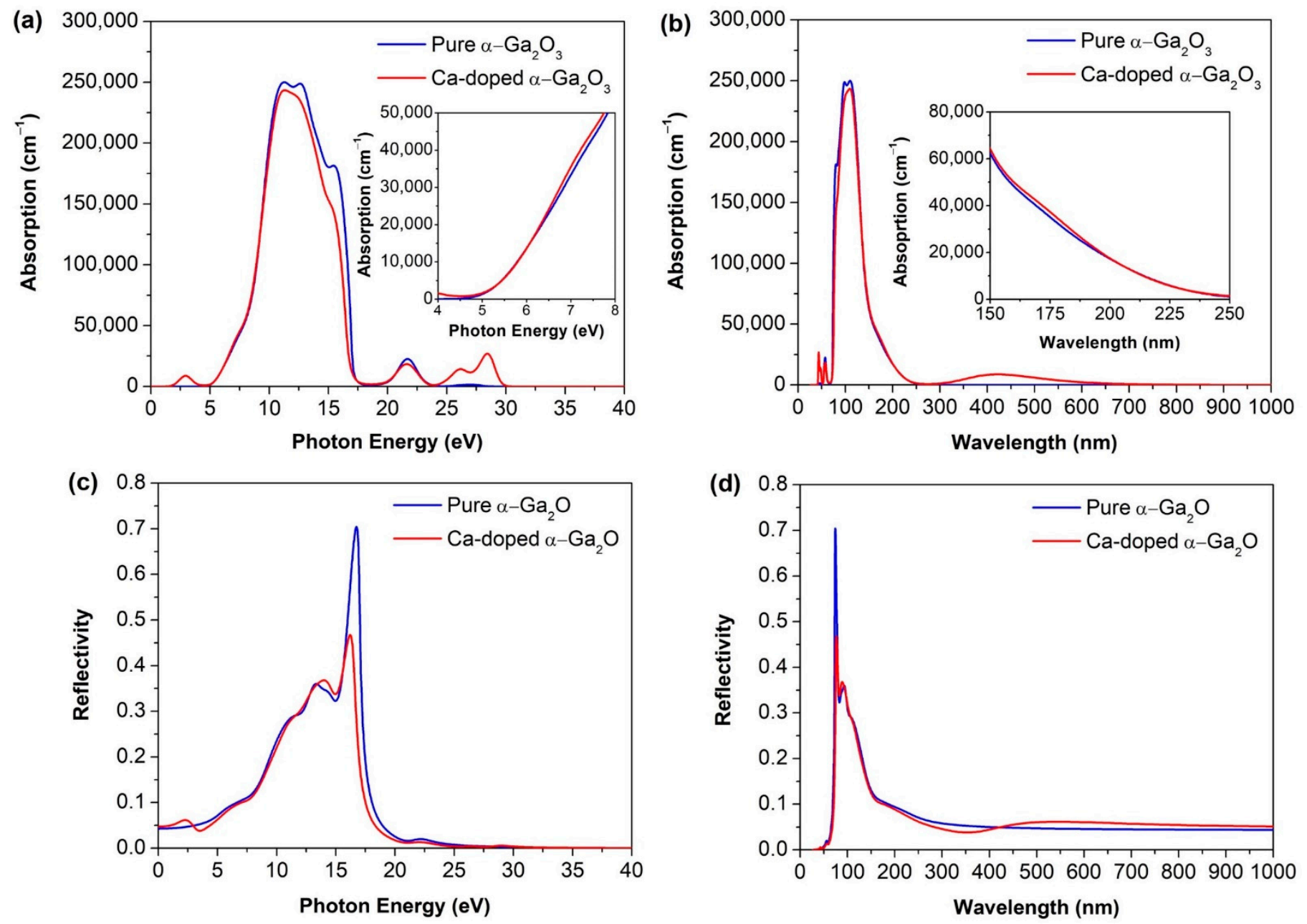

Figure 7. The absorption spectrum of (a) intrinsic $\alpha-\mathrm{Ga}_{2} \mathrm{O}_{3}$ and Ca-doped $\alpha-\mathrm{Ga}_{2} \mathrm{O}_{3}$ in energy, (b) intrinsic $\alpha-\mathrm{Ga}_{2} \mathrm{O}_{3}$ and Ca-doped $\alpha-\mathrm{Ga}_{2} \mathrm{O}_{3}$ in wavelength, the reflectivity of (c) intrinsic $\alpha-\mathrm{Ga}_{2} \mathrm{O}_{3}$ and Ca-doped $\alpha-\mathrm{Ga}_{2} \mathrm{O}_{3}$ in energy, and (d) intrinsic $\alpha-\mathrm{Ga}_{2} \mathrm{O}_{3}$ and $\mathrm{Ca}$-doped $\alpha-\mathrm{Ga}_{2} \mathrm{O}_{3}$ in wavelength window regime.

\section{Conclusions}

The substitutional Ca doping on the $\alpha-\mathrm{Ga}_{2} \mathrm{O}_{3}$ electronic, structural, and optical properties was studied through a first-principles calculation based on the DFT. The Ca doping predominantly affects the band structure and optical properties of pure $\alpha-\mathrm{Ga}_{2} \mathrm{O}_{3}$. The DFT-LDA calculated bandgap of $\alpha-\mathrm{Ga}_{2} \mathrm{O}_{3}$ is decreased to $2.950 \mathrm{eV}$ after Ca doping and the forbidden bandwidth appeared at the top of the valance band. The results obtained show that Ca-doped $\alpha-\mathrm{Ga}_{2} \mathrm{O}_{3}$ is an obvious variation of energy band structures and the charge density distribution. The acceptor energy states are composed of Ca $3 p$ and O $2 p$ orbital states. The Ca-doped $\alpha-\mathrm{Ga}_{2} \mathrm{O}_{3}$ dynamic dielectric function is observed. The most important absorption peak shifted in the visible regime; it realizes $p$-type $\alpha-\mathrm{Ga}_{2} \mathrm{O}_{3}$ but not a strong $p$-type candidate for optoelectronic device application. However, the lack of experimental results about the optical properties of Ca doped $\alpha-\mathrm{Ga}_{2} \mathrm{O}_{3}$ requires further experimental works to compare with our simulation results.

Author Contributions: Formal analysis, Investigation, Writing- original draft, Writing- review, and editing. A.K.M.; Assistance of analysis and giving an opinion regarding the paper, L.K.P.; Conceptualization, Methodology, Validation, Correction, Supervision, Project administration, M.A.M.; Co-supervision, Project administration, M.A.S.M.H. and R.B.; Provide facilities for conducting simulation analysis work, Validation, Correction, M.F.M.T. and M.H.S. All authors have read and agreed to the published version of the manuscript. 
Funding: This work is supported in part by the Universiti Kebangsaan Malaysia grant No. DIP-2019-018.

Data Availability Statement: No new data were created or analyzed in this study. Data sharing is not applicable to this article.

Conflicts of Interest: The authors declare no conflict of interest.

\section{References}

1. Dang, G.T.; Kawaharamura, T.; Furuta, M.; Allen, M.W. Mist-CVD Grown Sn-Doped $\alpha \alpha-G a 2 O 3$ MESFETs. IEEE Trans. Electron Devices 2015, 62, 3640-3644. [CrossRef]

2. Oda, M.; Tokuda, R.; Kambara, H.; Tanikawa, T.; Sasaki, T.; Hitora, T. Schottky barrier diodes of corundum-structured gallium oxide showing on-resistance of $0.1 \mathrm{~m} \Omega \cdot \mathrm{cm} 2$ grown by MIST EPITAXY ${ }^{\circledR}$. Appl. Phys. Express 2016, 9, 021101. [CrossRef]

3. Chen, X.; Xuanhu, C.; Zhou, D.; Yang, S.; Ren, F.-F.; Lu, H.; Tang, K.; Gu, S.; Zhang, R.; Zheng, Y.; et al. Solar-Blind Photodetector with High Avalanche Gains and Bias-Tunable Detecting Functionality Based on Metastable Phase $\alpha-G a 2 \mathrm{O} / \mathrm{ZnO}$ Isotype Heterostructures. ACS Appl. Mater. Interfaces 2017, 9, 36997-37005. [CrossRef] [PubMed]

4. Wang, X.; Xu, Q.; Li, M.; Shen, S.; Wang, X.; Wang, Y.; Feng, Z.; Shi, J.; Han, H.; Li, C. Photocatalytic Overall Water Splitting Promoted by an $\alpha-\beta$ phase Junction on Ga2O3. Angew. Chem. 2012, 124, 13266-13269. [CrossRef]

5. Fujita, S.; Oda, M.; Kaneko, K.; Hitora, T. Evolution of corundum-structured III-oxide semiconductors: Growth, properties, and devices. Jpn. J. Appl. Phys. 2016, 55, 1202A3. [CrossRef]

6. Furthmüller, J.; Bechstedt, F. Quasiparticle bands and spectra of Ga2O3 polymorphs. Phys. Rev. B 2016, 93, 115204. [CrossRef]

7. He, H.; Orlando, R.; Blanco, M.A.; Pandey, R.; Amzallag, E.; Baraille, I.; Rérat, M. First-principles study of the structural, electronic, and optical properties ofGa2O3in its monoclinic and hexagonal phases. Phys. Rev. B 2006, 74, 1-8. [CrossRef]

8. Patrick, L.; Choyke, W.J.; Hamilton, D.R. Luminescence of4HSiC, and Location of Conduction-Band Minima in SiC Polytypes. Phys. Rev. 1965, 137, A1515-A1520. [CrossRef]

9. De Paula, W.J.; Tavares, P.L.; Pereira, D.D.C.; Tavares, G.M.; Silva, F.L.; Almeida, P.S.; Braga, H.A.C. A review on gallium nitride switching power devices and applications. In Proceedings of the 2017 Brazilian Power Electronics Conference (COBEP), Juiz de Fora, Brazil, 19-22 November 2017; pp. 1-7.

10. Sabino, F.P.; Cai, X.; Wei, S.-H.; Janotti, A. Bismuth-doped Ga2O3 as a candidate for p-type transparent conducting material. arXiv 2019, arXiv:1906.00840.

11. Tadjer, M.J.; Lyons, J.L.; Nepal, N.; Freitas, J.A.; Koehler, A.D.; Foster, G.M. Editors' Choice-Review-Theory and Characterization of Doping and Defects in $\beta-G a 2 O 3$. ECS J. Solid State Sci. Technol. 2019, 8, Q3187-Q3194. [CrossRef]

12. Higashiwaki, M.; Kuramata, A.; Murakami, H.; Kumagai, Y. State-of-the-art technologies of gallium oxide power devices. J. Phys. D: Appl. Phys. 2017, 50, 333002. [CrossRef]

13. Varley, J.B.; Weber, J.R.; Janotti, A.; Van De Walle, C.G. Oxygen vacancies and donor impurities in $\beta$-Ga2O3. Appl. Phys. Lett. 2010, 97, 142106. [CrossRef]

14. Du, X.; Li, Z.; Luan, C.; Wang, W.; Wang, M.; Feng, X.; Xiao, H.; Ma, J. Preparation and characterization of Sn-doped $\beta-G a 2 O 3$ homoepitaxial films by MOCVD. J. Mater. Sci. 2015, 50, 3252-3257. [CrossRef]

15. Lovejoy, T.C.; Chen, R.; Zheng, X.; Villora, E.G.; Shimamura, K.; Yoshikawa, H.; Yamashita, Y.; Ueda, S.; Kobayashi, K.F.; Dunham, S.T.; et al. Band bending and surface defects in $\beta$-Ga2O3. Appl. Phys. Lett. 2012, 100, 181602. [CrossRef]

16. Fitzpatrick, T.; Munby, I. Knowledge of word associations. In Dimensions of Vocabulary Knowledge; Palgrave Macmillan: Basingstoke, UK, 2013; pp. 92-105.

17. Tang, C.; Sun, J.; Lin, N.; Jia, Z.; Mu, W.; Tao, X.; Zhao, X. Electronic structure and optical property of metal-doped Ga2O3: A first principles study. RSC Adv. 2016, 6, 78322-78334. [CrossRef]

18. Dong, L.; Yu, J.; Zhang, Y.; Jia, R. Elements ( $\mathrm{Si}, \mathrm{Sn}$, and Mg) doped $\alpha$-Ga2O3: First-principles investigations and predictions. Comput. Mater. Sci. 2019, 156, 273-279. [CrossRef]

19. Clark, S.J.; Segall, M.D.; Pickard, C.J.; Hasnip, P.J.; Probert, M.I.J.; Refson, K.; Payne, M.C. First principles methods using CASTEP. Z. Krist. Cryst. Mater. 2005, 220, 567-570. [CrossRef]

20. Zhang, L.; Yan, J.; Zhang, Y.; Li, T.; Ding, X. First-principles study on electronic structure and optical properties of N-doped P-type $\beta$-Ga2O3. Sci. China Ser. G Phys. Mech. Astron. 2011, 55, 19-24. [CrossRef]

21. Smith, J.; Jones, S.; White, L. Rapid Communication. Gastroenterol 1977, 72, 193. [CrossRef]

22. Perdew, J.P.; Burke, K.; Ernzerhof, M. Generalized Gradient Approximation Made Simple. Phys. Rev. Lett. 1996, 77, 3865. [CrossRef]

23. Pfrommer, B.G.; Côté, M.; Louie, S.G.; Cohen, M.L. Relaxation of Crystals with the Quasi-Newton Method. J. Comput. Phys. 1997, 131, 233-240. [CrossRef]

24. Liu, X.; Stoffel, R.; Dronskowski, R. Syntheses, Crystal Structures, and Vibrational Properties of Two Lead Azide Halides PbN 3 X. (X= Cl, Br). Z. Anorg. Allg. Chem. 2020, 646, 1525-1530. [CrossRef]

25. Fischer, T.H.; Almlof, J. General Methods for geometry and wave function optimization. J. Phys. Chem. 1992, 96, 9768-9774. [CrossRef]

26. Marezio, M.; Remeika, J.P. Bond Lengths in the $\alpha-G a 2 O 3$ Structure and the High-Pressure Phase of Ga2-xFexO3. J. Chem. Phys. 1967, 46, 1862-1865. [CrossRef]

27. Yamaguchi, K. First principles study on electronic structure of $\beta-G a 2 O 3$. Solid State Commun. 2004, 131, 739-744. [CrossRef] 
28. Shinohara, D.; Fujita, S. Heteroepitaxy of Corundum-Structured $\alpha$-Ga2O3Thin Films on $\alpha$-Al2O3Substrates by Ultrasonic Mist Chemical Vapor Deposition. Jpn. J. Appl. Phys. 2008, 47, 7311-7313. [CrossRef]

29. Shaukat, A.; Saeed, Y.; Nazir, S.; Ikram, N.; Tanveer, M. Ab initio study of structural, electronic and optical properties of Ca1-xSrxS compounds. Phys. B: Condens. Matter 2009, 404, 3964-3972. [CrossRef]

30. Feng, J.; Xiao, B.; Xing, J.; Zhou, C.; Du, Y.; Zhou, R. Optical properties of new photovoltaic materials: AgCuO2 and Ag2Cu2O3. Solid State Commun. 2009, 149, 1569-1573. [CrossRef]

31. Ma, X.; Zhang, Y.; Dong, L.; Jia, R. First-principles calculations of electronic and optical properties of aluminum-doped $\beta$-Ga2O3 with intrinsic defects. Results Phys. 2017, 7, 1582-1589. [CrossRef] 